\title{
EfFect of Process Parameters on the Total Heat Damaged Zone (HDZ) DURING MiCRO- EDM OF Plastic MOLd STEEL 1.2738
}

\author{
Dr. Govindan Puthumana \\ Post-Doctoral Researcher, Department of Mechanical Engineering \\ Technical University of Denmark, Lyngby.
}

\begin{abstract}
In micro electrical discharge machining, three subsurface layersare formed on the workpiece, they are; recast zone, heat affected zone and converted zone, primarily due to heating-quenching cycles. The HDZ in micro-EDM is characterized by cracks and weakness in the grain boundary and thermal residual stresses. This paper presents the effect of process parameters on the HDZ in micro-EDM of plastic mold steel 1.2738. As the energy of the sparks increases, the thickness of the HDZ increases and the average coefficient of correlation between energy and HDZ considering three different sections of the zone is 0.8099. Therefore, the effect of process parameters governing the discharge energy are analyzed; they are: average current (Ia), peak current (Ip) and pulse 'on-time' (Ton). An overall increase in heat-damaged zone thickness by $105 \%$ is observed with an increase in pulse on time.
\end{abstract}

\section{KEYWORDS :}

HDZ, micro-EDM, correlation, process parameters, analysis of means, regression analysis

\section{INTRODUCTION}

Micro-EDM is one of the advanced precision machining techniques, which involves complex interaction of thermal energy with the workpiece involving heating and cooling. The energy of the plasma helps removal of material from the workpiece surface, but at the same time, leads to formation of three types of zones around the machined area. These zones are: recast layer, heat affected zone and converted zone [1]. Due to the complexity in sparking phenomenon and material removal mechanisms, there are only a limited number of investigations on the effect of discharge energy on workpiece surface and sub-surface layers. The heat transfer in spark erosion process was analyzed and the distribution of thermal energy to different workpiece zones were studied in Ref. [2]. The studies involved development of heat transfer equations using finite difference method, prediction of crater shapes and analysis of thermal isotherms. Kumar et al. [3] have reviewed research works on workpiece surface modifications and influence of heating on the workpiece, tool and dielectric. The focus of their work was on effect of plasma heating and pyrolysis of liquid dielectric on the composition of the workpiece external surface and the HDZ. Thao et al. [4] have used experimental techniques for characterization of the heat-affected zone involving micro hardness measurement, Scanning Electron (SE) and Electron Backscatter Diffraction (EBSD) microscopy and Energy Dispersive X-ray (EDX) analysis. The recast layer in electrical discharge machining was studied using different techniques to understand the distribution of thermal energy [5]. The compositional variations of the recast layer was determined followed by inspection of the layer for micro-cracks or micro-voids, and measurement of micro-hardness. Two recent investigations [6-7] have showed that the size of the recast layer depends on the energy of sparking. It has been demonstrated that the die sinking EDM processing conditions influences the thickness of the martensitic dominated zone. Though 
the effect of processing conditions on macro die sinking EDM is established in a few investigations, the influence of process parameters on the micro-EDM process is reported in only a few research studies. Therefore, the objective of this paper is to analyze the effect of process parameters on the damaged zone in micro-EDM. In this regard, the work reported in Ref. [8] is referred and used for conducting this analysis. The relationship between discharge energy and thickness of heat-damaged zone is plotted for verification of the correlation. Furthermore, ANOVA and AOM methods are used to evaluate the effect of micro-EDM process parameters on the total thickness of heat damaged zone. The model equations are developed for HDZ that connects the process parameters.

\section{Correlation Between Discharge Energy aNd HDZ}

Several experimental investigations have revealed that the characteristics of the machined surface depends mainly on the discharge energy during EDM [2-3, 5-7]. The micro-EDM is also a thermal-energy based process, and therefore, a linear relationship between thickness of the HDZ and discharge energy is expected. The variation of HDZ with discharge energy is plotted for different sections, viz. hole entrance, parallel wall and end tip cone [8]. The methodology of the entire investigation including the present work is illustrated in Fig. 1. The present work involves the last three stages associated with establishment of empirical correlation, main effects analysis and regression modeling.

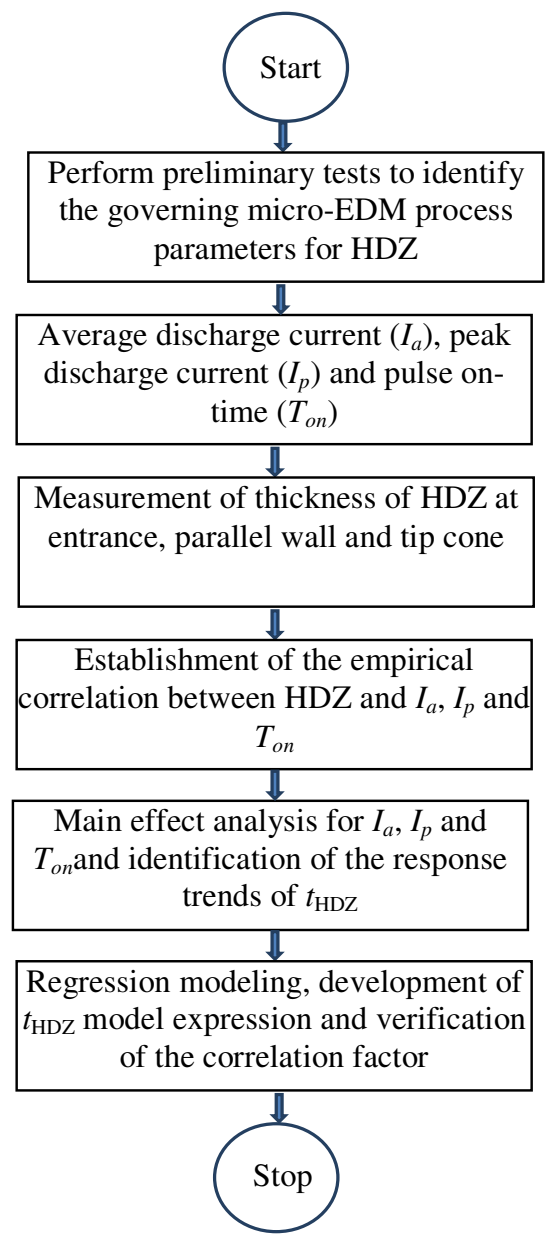

Fig.1 Flowchart exemplifying the whole methodology of investigation 
The results of the correlation of the thickness of heat-damaged zone with energy are presented in Fig. 2a-c. It is evident that the coefficient of correlation between thickness of HDZ and discharge energy are respectively $0.8305,0.8392$ and 0.7601 respectively for the three sections with different characteristics. The variation in coefficient of correlation at different sections could be because of a change in the rate of transfer of discharge energy to the workpiece surface due to difference in thermal conductivity and heat capacity between these sections.

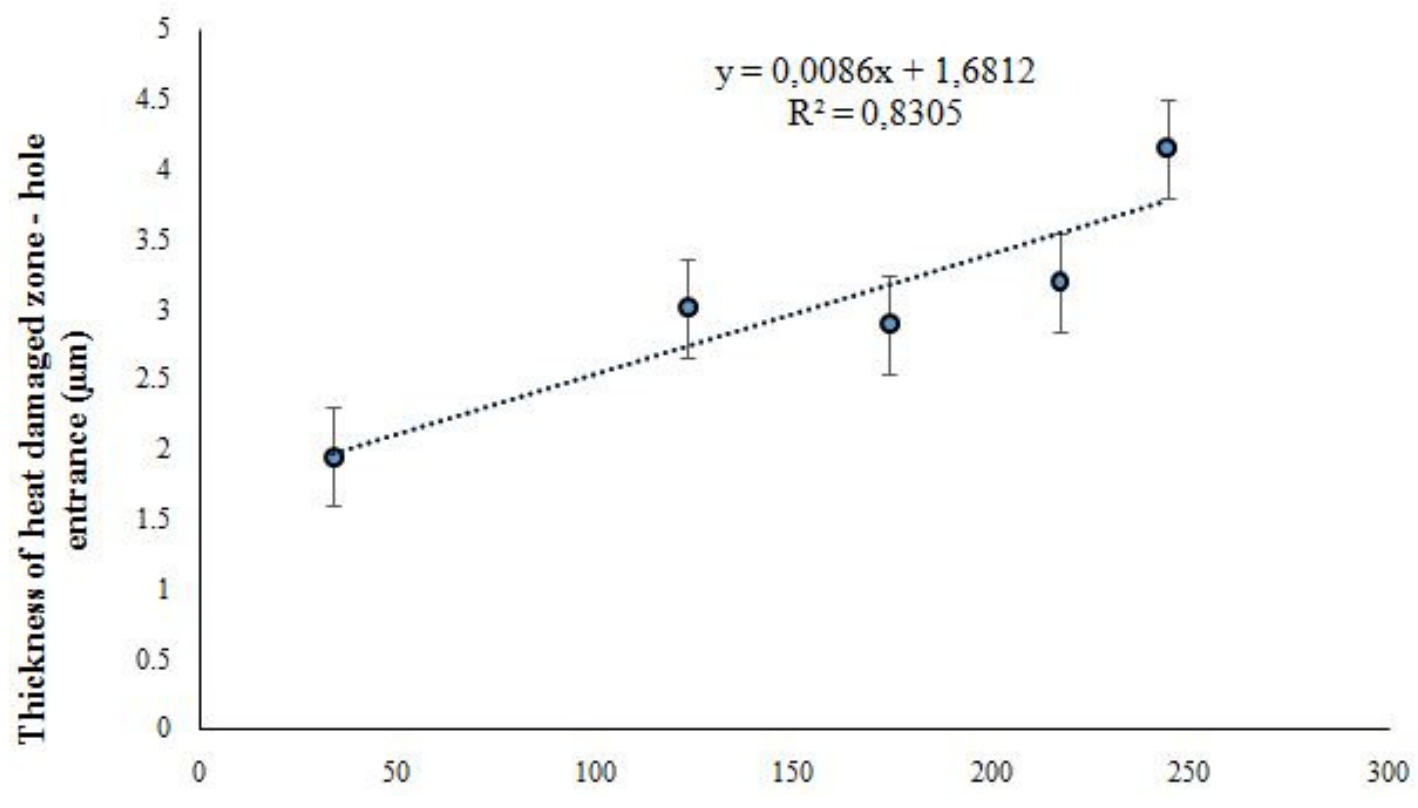

a. Discharge Energy ( $\mu \mathrm{J})$

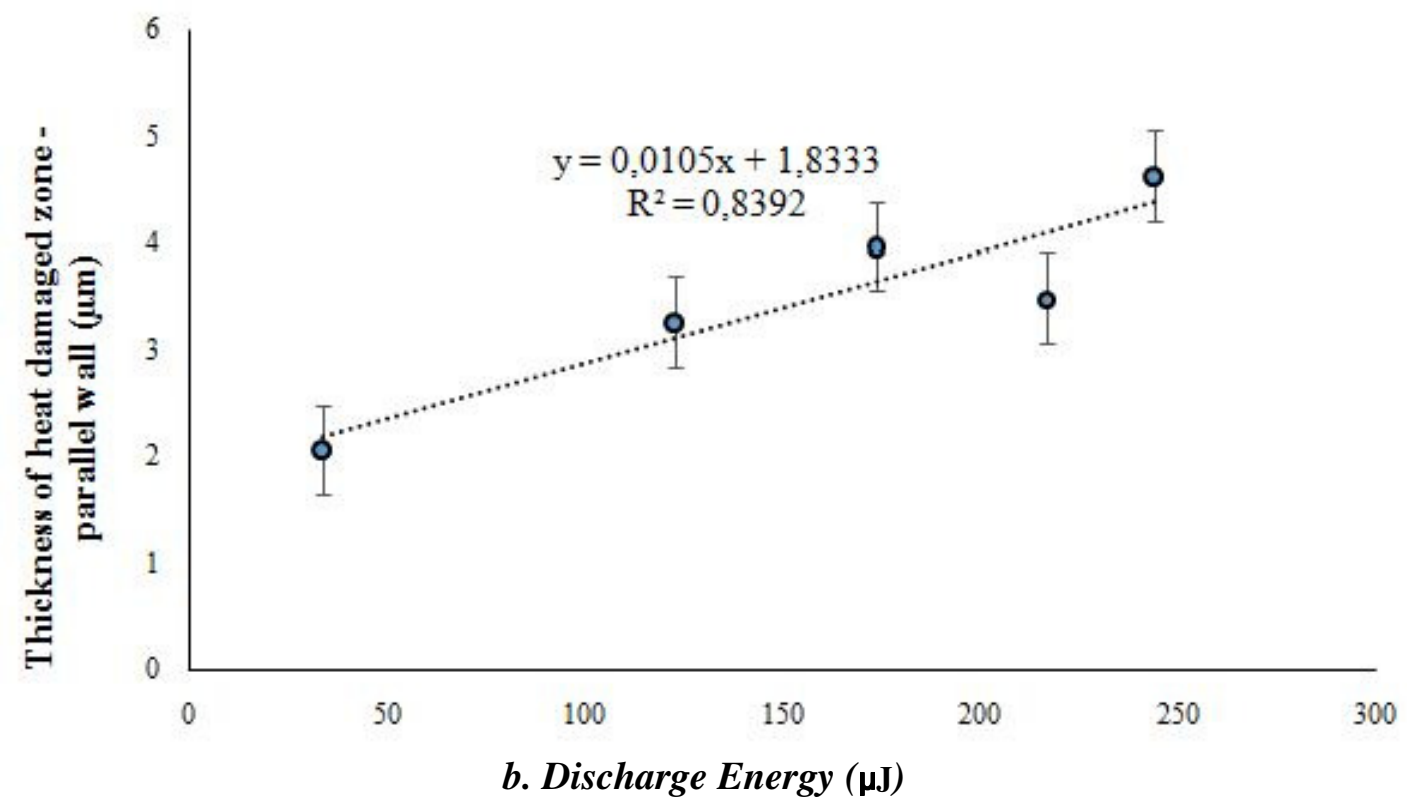




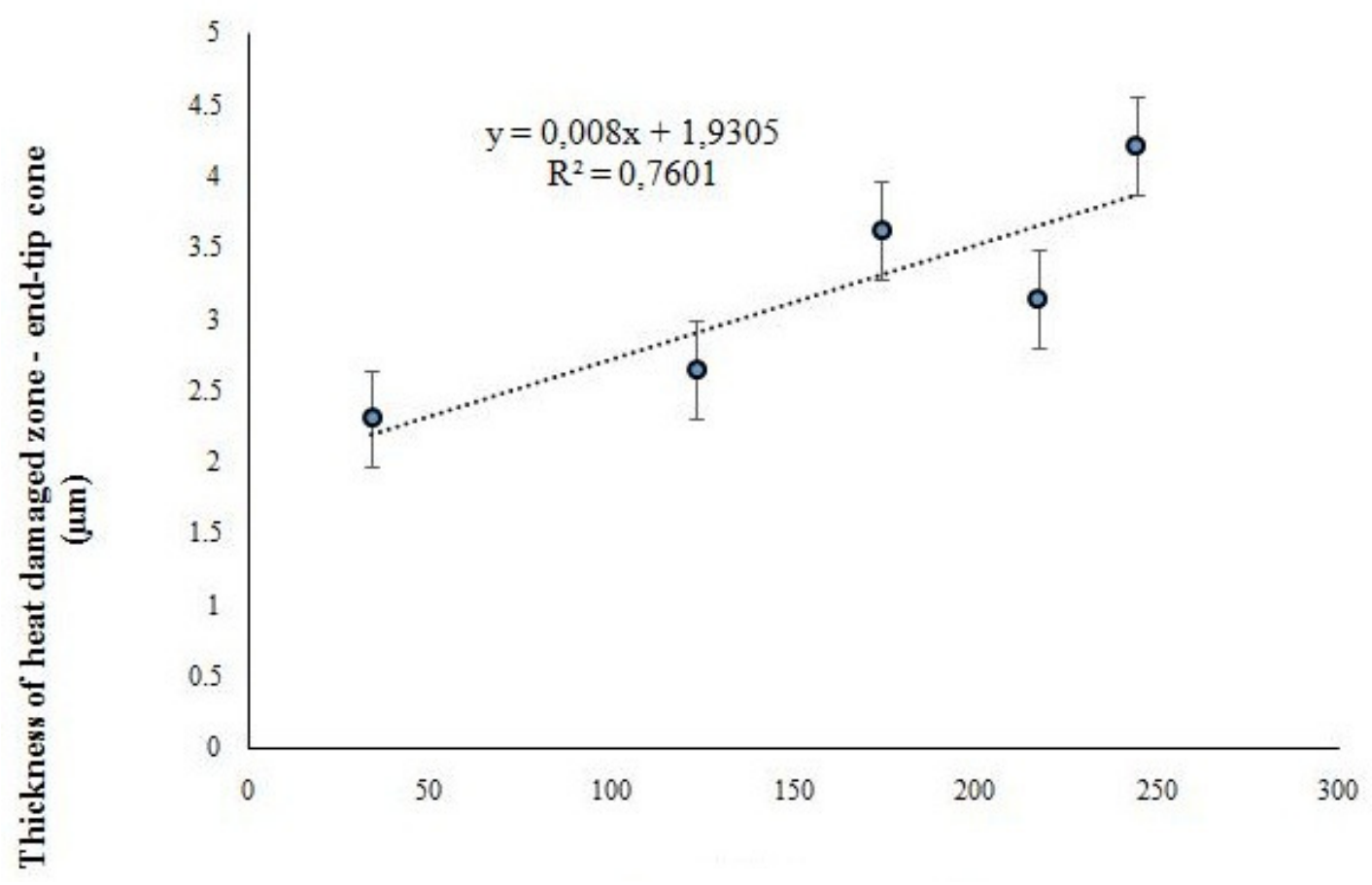

\section{c. Discharge Energy $(\mu \mathrm{J})$}

Fig. $2 a-c$ A variation of heat affected zone with discharge energy at different sections of workpiece, $a$. hole entrance, $b$. parallel wall, and $c$. end tip cone

\section{ANALYSIS OF HDZ}

The main effects of process parameters on the total thickness of HDZ have been analyzed and presented in Fig. 3a-c. Figs. 3- $b$ and 3-c show a clear trend of increase in thickness of HDZ with an increase in peak current as well as pulse on-time. $E$ is the total energy of a single discharge, give by:

$$
t_{\mathrm{HDZ}}=\mathrm{k} \times\left(\times V \times T_{\text {on }}\right) \ldots \ldots \ldots \ldots \ldots \ldots \ldots \ldots \ldots \ldots \ldots \ldots \ldots \ldots \ldots \ldots \ldots \ldots \ldots,
$$

where, $V$ is the discharge voltage, $I$ is the discharge current and $T_{o n}$ is the pulse duration. The total thickness of the HDZ can be expressed as:

$t_{\mathrm{HDZ}}=\mathrm{k} \times\left(\times V \times T_{o n}\right)$

where, $k$ is a constant. As the peak current increases from 6 to 11.52 A (by 92\%), an increase in thickness of HDZ by $106 \%$ is observed. This indicates that peak current has a direct influence on the thickness of the HDZ, $t_{\mathrm{HDZ}}(3-b)$, also mathematically expressed in eq. (2). However, at pulse currents above $11.52 \mathrm{~A}$, a decrease in $t_{\mathrm{HDZ}}$ by $19 \%$ can be seen. At higher discharge currents, an effect of energy on HAZ in laser machining similar to Ref. [9] could be seen. Moreover, the effect of discharge is on increasing the depth of hole. 


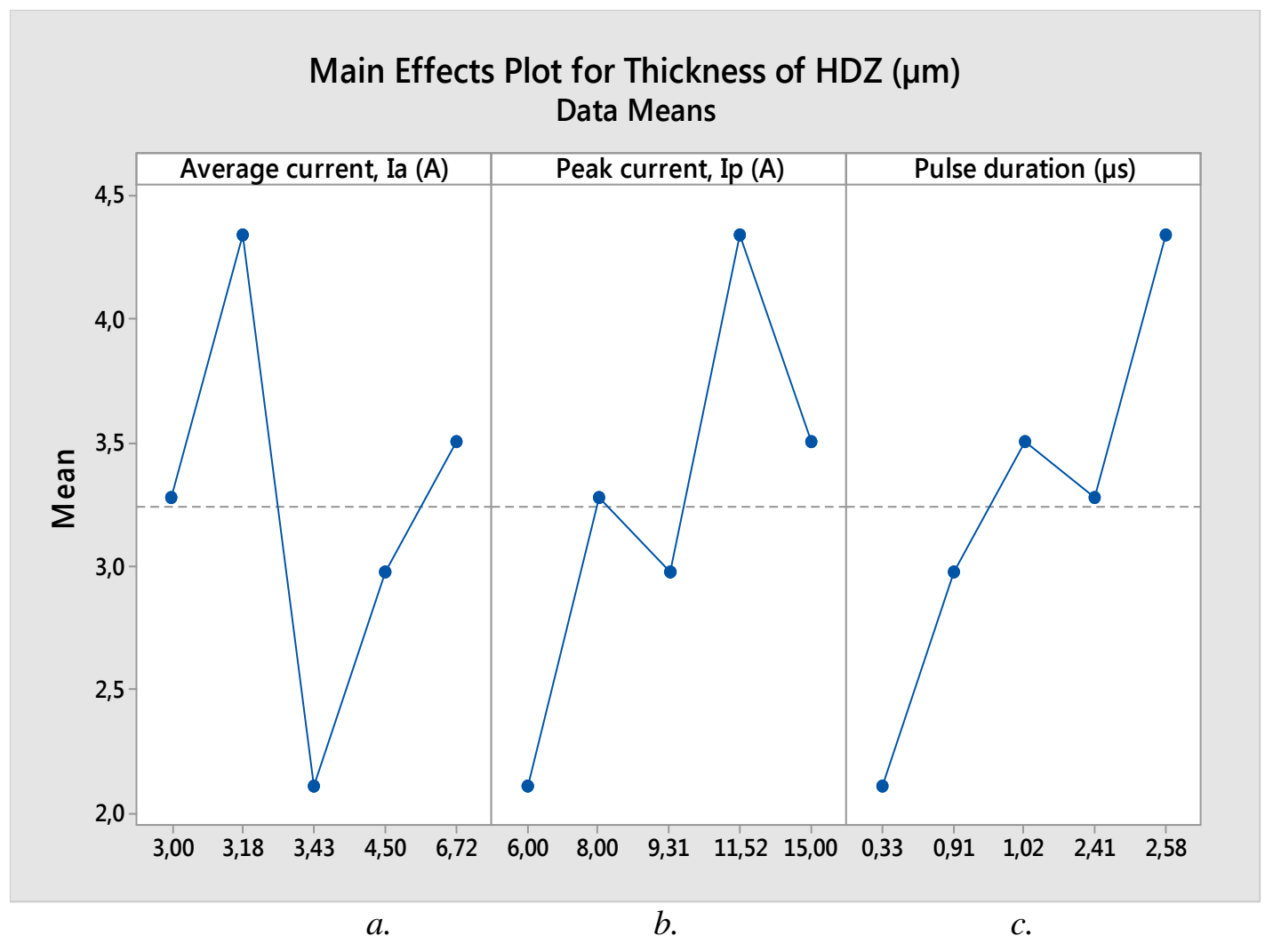

Fig. 3a-cEffects of average current (a), peak current (b) and pulse duration (b) on the thickness of heat damaged zone (HDZ)

The pulse on-time is a process parameter in micro-EDM that causes an increase in the amount of discharge energy delivered to the workpiece surface. As can be observed from Fig. 2-c, an overall increase in the $t_{\mathrm{HDZ}}$ by $105 \%$ is observed. This result has verified the relationships in eq. (1) and eq. (2).

\section{REGRESSION MODELING}

Regression analysis is a statistical tool for the study of relationships between variables. In this work, the effects of average current $\left(I_{a}\right)$, peak current $\left(I_{p}\right)$ and pulse on-time $\left(T_{o n}\right)$ on the thickness of HDZ is ascertained.

$$
\begin{aligned}
& t_{\mathrm{HDZ}}=1.825-0.447 \times I_{a}+0.3037 \times I_{p}+0.156 \times T_{o n} \\
& \mathrm{Rsq}=86.64 \%
\end{aligned}
$$

Using this model, the $t_{\mathrm{HDZ}}$ can be predicted based on a variation in the micro-EDM process parameters $I_{a}, I_{p}$ and $T_{o n}$. 


\section{Conclusions}

This paper presents an attempt to evaluate the effect of process parameters on the heat-damaged zone in micro-EDM of mold steel 1.2738. The mold steel 1.2738 has a wide variety of applications in molds, tools and die industry, and, also when the quality and integrity of surfaces are of great concern. The sudden heating during the discharge and rapid cooling of the workpiece surface by the liquid dielectric causes formation of a recast layer, micro-cracks and micro-pores. Based on this work on analysis of $t_{\mathrm{HDZ}}$, the following conclusions can be drawn:

- A correlation between thickness of the heat damaged zone thickness and discharge energy is established. A linear relationship has been observed. The coefficient of correlation at three selected sections on the workpiece are: $0.8305,0.8392$ and 0.7601 .

- An overall increase in heat-damaged zone thickness by $105 \%$ is observed with an increase in pulse on time. This could be due to a corresponding increase in discharge energy.

- With an increase in peak pulse current from 6 to $11.52 \mathrm{~A}$, an increase in thickness of heat damaged zone by $92 \%$ is obtained. However, a further increase in current causes a decrease in thickness of the zone by $19 \%$. This could be primarily because of the effect of focusing of electrons at higher electric fields in micro-EDM process, which is reflected on deepening of the hole machined.

- A regression model equation has been developed between the heat damaged zone thickness $\left(t_{\mathrm{HDZ}}\right)$ and the micro-EDM process parameters. The $\mathrm{R}$-sq value for the relationship has been found to be $86.64 \%$.

\section{ACKNOWLEDGEMENTS}

The author would like to acknowledge the support from H.C. Ørsted COFUND postdoc fellowship.

\section{REFERENCES}

[1] Jain, V. K. (2008), Advanced machining processes, Allied publishers pvt. Ltd.

[2] Banerjee, S., Prasad, B. V. S. S. S. and Mishra, P. K. (1997), Analysis of three-dimensional transient he $\mathrm{t}$ conduction for predicting wire erosion in the wire electrical discharge machining process, Journal of Materials Processing Technology, v65, n1-3, pp. 134-142.

[3] Kumar, S., Singh, R., Singh, T. P. and Sethi, B. L. (2009), Surface modification by electrical discharge machining: a review, Journal of Materials Processing Technology, v209, n8, pp. 3675-3687.

[4] Thao, O. and Joshi, S. S. (2008), Analysis of heat affected zone in the micro electric discharge machining, International Journal of Manufacturing Technology and Management, v13, n2-4, DOI: http://dx.doi.org/10.1504/IJMTM.2008.016771.

[5] Zhang, Y., Liu, Y., Ji, R. and Cai, B. (2011), Study of the recast layer of a surface machined by sinking electrical discharge machining using water-in-oil emulsion as dielectric, Applied surface science, v257, n14, pp.5987-5997.

[6] Steuer, P., Rebschlanger, A., Weber, O. and Bahre, D. (2014), The heat-affected zone in EDM and its influence on a followingPECM process,Procedia CIRP, v13, n1, pp.276-281.

[7] Liu, J. F. and Guo, Y. B. (2016), Modeling of White Layer Formation in Electric Discharge Machining (EDM) by Incorporating Massive Random Discharge Characteristics, Procedia CIRP, v42, n1, pp. 697-702.

[8] Ekmekci, B., Sayar, A., Opoz, T. T. and Erden, A. (2010), Characteristics of surface damage in micro electric discharge machining of micro holes, Advanced materials research, v83-86, n1, pp. 688-695.

[9] Alavi, S. H. and Harimkar, S. P. (2016), Evolution of geometric and quality features during ultrasonic vibration-assisted continuous wave laser surface drilling, Journal of Materials Processing Technology, v232, n1, pp. 52-62. 